\title{
Laparoscopic Nephron-Sparing Surgery for a Renal Mass: 1-Year Minimum Follow-Up
}

BRIAN D. SEIFMAN, M.D., BRENT K. HOLLENBECK, M.D., and J. STUART WOLF, JR., M.D.

\begin{abstract}
Background and Purpose: Because of the explosion of laparoscopy in urology coinciding with the excellent results of open nephron-sparing surgery (NSS) for small renal masses, laparoscopic NSS has become an alternative to an open surgical approach. We report our results with laparoscopic NSS in patients who have had a minimum of 1 year of follow-up.

Patients and Methods: All consecutive laparoscopic partial nephrectomies from November 1998 through February 2002 were assessed. The mean patient age, body mass index, and American Society of Anesthesiology score were 57.1 years, $28.5 \mathrm{~cm} / \mathrm{kg}^{2}$, and 2.0 , respectively. The procedures were performed using hand-assisted ( $N=28)$ or standard $(\mathbf{N}=12)$ laparoscopic techniques. Hospital records were reviewed in order to obtain operative, perioperative, and follow-up data.

Results: The median operating room time, estimated blood loss, and hospital stay were 184 minutes, 300 $\mathrm{mL}$, and 2.0 days, respectively. No patients were converted to an open surgical procedure. Four patients (10\%) required a blood transfusion, and one $(2.5 \%)$ had a postoperative urinoma. The mean tumor size was $2.3 \mathrm{~cm}$. Twenty-nine lesions were renal-cell carcinoma, and 11 were benign. With a mean CT scan follow-up of 100.0 weeks, there has not been any recurrence of renal-cell carcinoma.

Conclusion: Laparoscopic NSS can be performed with acceptable complication rates, which will continue to decrease as newer methods of controlling hemostasis are developed. Although follow-up is fairly short, no renal-cell carcinoma recurrences have appeared. At this point in time, the oncologic efficacy of a laparoscopic approach appears to mirror that of the open surgical technique.
\end{abstract}

\section{INTRODUCTION}

$\mathbf{H}$ ISTORICALLY, RENAL-CELL CARCINOMA (RCC) has been managed by open surgical radical nephrectomy. However, as operative techniques and postoperative care have improved, partial nephrectomy or nephron-sparing surgery (NSS) is being used increasingly to manage small $(<4-\mathrm{cm})$ renal masses. ${ }^{1}$ For these masses, the long-term results of open surgical NSS are comparable to those of a radical nephrectomy, which has made NSS an acceptable management option. ${ }^{2-4}$

Because of the explosion of laparoscopy in urology coinciding with the excellent results of open NSS for small renal masses, in 1994, the first report of laparoscopic NSS for RCC was published. ${ }^{5}$ However, the technical challenges of repairing collecting-system injuries laparoscopically and obtaining hemostasis have hindered the widespread use of laparoscopic partial nephrectomies. Herein, we describe our results with lapa- roscopic NSS in patients who have had at least 1 year of follow-up.

\section{PATIENTS AND METHODS}

Institutional Review Board approval was obtained.

All consecutive laparoscopic partial nephrectomies from November 1998 through February 2002 were assessed. All procedures were directed by one surgeon (JSW). They were performed using a hand-assisted laparoscopic technique ${ }^{6}$ except that when the tumor was exophytic $(<5-\mathrm{mm}$ penetration into the parenchyma), standard laparoscopic techniques were employed.

Hospital records were reviewed in order to obtain operative, perioperative, and follow-up data. The recommended followup entailed a CT scan, chest radiograph, and serum chemistry

Department of Urology, University of Michigan Health System, Ann Arbor, Michigan. 
Table 1. Demographics and Tumor Characteristics

\begin{tabular}{lc}
\hline Mean age & 57.1 years \\
Mean body mass index & $28.5 \mathrm{~cm} / \mathrm{kg}^{2}$ \\
Mean American Society of & 2.0 \\
$\quad$ Anesthesiology score & \\
Male (\%) & $27(68)$ \\
Left-sided lesion (\%) & $22(55)$ \\
Location of tumor & \\
$\quad$ Upper pole & 12 \\
Mid-renal & 13 \\
Lower pole & 15 \\
\hline
\end{tabular}

assays every 6 months for the first 2 years, then yearly thereafter. The frequency of imaging studies was decreased for lowgrade small $(<2-\mathrm{cm})$ tumors. Bivariate analyses were performed to determine associations that could be predictive of complications and conversion from standard laparoscopy to hand assistance.

Forty laparoscopic partial nephrectomies were performed during the study period. Thirty-nine were transperitoneal (28 with hand assistance and 11 with standard laparoscopy) and one was retroperitoneal. The demographic and tumor characteristics are provided in Table 1.

Nearly all patients $(\mathrm{N}=36)$ had presented with an incidental renal mass. Two patients had an evaluation prompted by hematuria and another two by abdominal/flank pain. The indication for partial nephrectomy was absolute in 9, relative in 18 , and elective in 13 .

\section{RESULTS}

\section{Hospital course}

The median operating room time was 184 minutes (range 115-328 minutes) with a median estimated blood loss of 300 $\mathrm{mL}$ (range $50-1850 \mathrm{~mL}$ ). The median hospital stay was 2.0 days (range 1-37 days).

Four patients (10\%) required a blood transfusion postoperatively. In the hand-assisted procedures, hemostasis was obtained with fibrin-soaked Gelfoam on the base of the resection site, with the argon-beam coagulator sealing the edges of the resection. ${ }^{6}$ In standard laparoscopic cases, a combination of bipolar electrocautery and the argon-beam coagulator was used for hemostasis. The renal hilum was not clamped in any of these cases.

Complications were categorized as an early postoperative (during the hospital stay) or late (within 30 days after discharge) and as major (prolonged the hospital stay, necessitated an operative procedure) or any (all of the categories). Eleven early complications occurred in 10 patients $(25 \%)$ and four late complications in 3 patients $(7.5 \%)$ (Table 2$)$. One patient had delayed postoperative hemorrhage, and one patient had a urinoma that resolved after ureteral stent placement. Both of these complications occurred within the first 18 cases. Four patients (10\%) suffered six major complications (deep venous thrombosis, pulmonary embolism, urine leak, prolonged intubation, postoperative hemorrhage, pancreatitis). There has been only one major complication (pancreatitis) in the last 22 cases.

Longer operative time was associated with early postoperative complications $(P=0.0002)$, a major complication $(P=$ $0.013)$, any complication $(P=0.004)$, and a need for a blood transfusion $(P=0.003)$. The ASA score had no effect on complication rates; however, body mass index was associated with late postoperative complications $(P=0.045)$. Not surprisingly, patients who suffered any complication or needed a transfusion had a longer hospital stay ( $P=0.007$ and 0.0040 , respectively).

Four patients were converted from standard laparoscopy to hand assistance because of uncontrolled bleeding, but no patients were converted to an open surgical procedure. The variables associated with a higher rate of conversion include increased age $(P=0.017)$, longer operative time $(P=0.018)$, and a higher estimated blood loss $(P=0.033)$. Although the differences were not statistically significant, men and patients with larger tumors were more likely to be converted $(P=0.08$ and 0.099, respectively).

\section{Tumor characteristics}

The mean tumor size was $2.3 \mathrm{~cm}$. Twenty-nine lesions were RCC, and 11 were benign ( 4 oncocytomas, 2 angiomyolipomas, 2 cysts, and 3 other lesions). All margins were negative, except for one. In this case, enucleation was performed on a

Table 2. Number of Patients Having Complications

\begin{tabular}{lcc}
\hline & Early complications & Late complications \\
\hline Urinary retention & 3 & 1 \\
Deep venous thrombosis $^{\mathrm{a}}$ & 1 & 0 \\
Urinoma $^{\mathrm{a}}$ & 1 & 0 \\
Hemorrhage $^{\mathrm{a}}$ & 1 & 0 \\
Pulmonary embolus $^{\mathrm{a}}$ & 1 & 0 \\
Prolonged intubation $^{\mathrm{a}}$ & 1 & 0 \\
Cellulitis $_{\text {Pancreatitis }}^{\text {a }}$ & 2 & 0 \\
Gastrointestinal hemorrhage $_{\text {Febrile urinary-tract infection }}$ & 1 & 0 \\
Small-bowel obstruction & 0 & 1 \\
$\quad$ Total & 0 & 1 \\
\end{tabular}

${ }^{\mathrm{a}}$ Major complication. 
Table 3. Methods of Hemostasis in NSS

\begin{tabular}{ll}
\hline Timing & \multicolumn{1}{c}{ Method } \\
\hline Prior to resection & $\begin{array}{l}\text { Renal artery and/or vein clamp } \\
\text { Radiofrequency coagulation } \\
\text { Microwave tissue coagulator }\end{array}$ \\
During resection & $\begin{array}{l}\text { Harmonic Scalpel/Shears } \\
\text { Nd:YAG laser } \\
\end{array}$ \\
& Bipolar cautery \\
Argon-beam coagulator \\
After resection & Fibrin-glue soaked gelatin sponge \\
& Gelatin resorcinol formaldehyde glue \\
\hline
\end{tabular}

second, incidental mass when a frozen-section examination suggested a papillary RCC.

To date, there has not been any recurrence of RCC. The mean chest radiography follow-up is 107.3 weeks, and the mean CT follow-up is 100.0 weeks.

\section{DISCUSSION}

Nephron-sparing surgery has become an accepted management option for renal masses $<4 \mathrm{~cm}$. Open surgical partial nephrectomies have demonstrated long-term cancer control equivalent to that obtained with radical nephrectomies. ${ }^{3}$ The long-term results of a laparoscopic approach are currently being investigated. The current study addresses this issue by having a minimum of 1 year follow-up, and there have yet to be any recurrences.

The greatest challenge in performing a laparoscopic partial nephrectomy is hemostasis. This was the reason for converting four patients from standard laparoscopy to hand assistance. Two variables we found to be associated with conversion are intuitive: longer operating time (additional time needed for conversion) and higher estimated blood loss (reason for conversion). There was a trend toward larger tumors necessitating conversion $(P=0.099)$. Although the variable was not evaluated here, the depth of penetration into the renal parenchyma may provide more insight. Furthermore, the renal hilum was not clamped in any of these cases. This may have also prevented conversion to hand assistance.

As hemostasis is the greatest challenge to laparoscopic NSS, various methods have been developed. These methods can be performed either prior to removing the tumor, during the resection, or after the tumor is removed (Table 3). The simplest way to control blood loss prior to resecting the tumor is to clamp the renal artery. The advantage of clamping the renal hilum is that the tumor can be excised with excellent visibility. Furthermore, blood loss and operative time can be decreased with minimal clinical difference in the serum creatinine level. ${ }^{7}$ Our recent experience with clamping of the hilum has been similarly favorable. Of the 27 cases we have performed in the last year, which are not included in this series because follow-up has been too short, 19 were performed with hand assistance and 17 with vascular clamping. We routinely obtain vascular control if the depth of penetration of the mass is $>5 \mathrm{~mm}$. Although we have been satisfied with the oncologic results in the series reported herein, vascular control allows the application of laparoscopy to more technically challenging partial nephrectomies. The major criticism of clamping is that reliable hypothermia is not obtained. Renal hypothermia has been attempted either by irrigating the renal pelvis through a retrograde ureteral access catheter or by placing the kidney in an endoscopic bag and cooling it with slush placed through a port site. ${ }^{8}$ The effectiveness and reliability of either of these techniques have yet to be proven.

Other methods used for hemostasis prior to resecting the lesion are a microwave tissue coagulator ${ }^{9}$ or radiofrequency coagulation. ${ }^{10}$ Despite coagulation, accurate pathology reports were still able to be obtained. Both of these methods are limited by the small number of institutions having expertise in their use.

Many laparoscopic instruments are available to assist with hemostasis during resection of the tumor. The options include the Harmonic Scalpel/Shears, ${ }^{11-13}$ the Nd:YAG laser, ${ }^{6,14-15}$ and bipolar cautery. ${ }^{16}$ However, none of these instruments alone, or in combination, provides reliable hemostasis without added measures.

After removal of the tumor, either the argon-beam coagulator, suturing, or topical sealants can be used. Although reported to be successful, ${ }^{7,8}$ the technical challenge of laparoscopic suturing has limited its widespread application. Topical sealants consist of either a gelatin sponge soaked with fibrin glue $^{6}$ or gelatin resorcinol formaldehyde glue. ${ }^{13}$ With experience, both of these sealants are useful hemostatic maneuvers. However, the gelatin resorcinol formaldehyde glue may not be adequate to seal a rent in the collecting system, as two patients in one series $(16.7 \%)$ developed a urinary leak despite placement of a ureteral stent. ${ }^{13}$

The most commonly cited complications of NSS are hemorrhage and urinary fistula. In evaluating the published series of laparoscopic partial nephrectomy covering more than 25 patients, our complication rate is consistent with others (Table 4).

Table 4. Published Series of Laparoscopic NSS with Minimum of 25 Patients

\begin{tabular}{|c|c|c|c|c|c|}
\hline Source & $\begin{array}{l}\text { No. of } \\
\text { patients }\end{array}$ & $\begin{array}{c}\text { No. }(\%) \\
\text { hemorrhage }\end{array}$ & $\begin{array}{c}\text { No. }(\%) \text { urinary } \\
\text { fistula }\end{array}$ & $\begin{array}{c}\text { Mean } \\
\text { follow-up } \\
\text { (mos) }\end{array}$ & $\begin{array}{l}\text { No. local } \\
\text { recurrences }\end{array}$ \\
\hline Guillonneau et $\mathrm{al}^{7}$ & 28 & $2(7)$ & $0(0)$ & - & - \\
\hline Jeschke et al $^{11}$ & 51 & $1(2)$ & $3(6)$ & 34.2 & 0 \\
\hline Rassweiler et al ${ }^{16}$ & 53 & $5(9)$ & $5(9)$ & 24 & 0 \\
\hline Gill et $\mathrm{al}^{8}$ & 50 & $2(4)$ & $1(2)$ & 7.2 & 0 \\
\hline Current series & 40 & $1(3)$ & $1(3)$ & 24.4 & 0 \\
\hline
\end{tabular}


As with most laparoscopic procedures, a higher complication rate occurs early in the learning curve. The current series is no different, as none of the last 22 patients suffered a major complication except one case of pancreatitis.

Laparoscopy in urology is relatively young. Certainly, laparoscopic partial nephrectomy is in its infancy and is evolving. Even though follow-up is relatively short, it is notable that no local recurrences have yet been reported.

\section{CONCLUSION}

The long-term results of open surgical NSS and the increased use of laparoscopy in urology have provided the basis for laparoscopic NSS. Such operations can be performed with acceptable complication rates, which will continue to decrease as newer methods of hemostasis are developed. Although followup is fairly short, no local RCC recurrences have been reported in the literature to date. The oncologic efficacy of a laparoscopic approach, at this point in time, appears to mirror that of the open surgical technique.

\section{REFERENCES}

1. Uzzo RG, Novick AC. Nephron sparing surgery for renal tumors: Indications, techniques, and outcomes. J Urol 2001;166:6-18.

2. Filipas D, Fichtner J, Spix C, et al. Nephron-sparing surgery of renal cell carcinoma with a normal opposite kidney: Long-term outcome in 180 patients. Urology 2000;56:387-392.

3. Fergany AF, Hafez KS, Novick AC. Long-term results of nephron sparing surgery for localized renal cell carcinoma: 10-year followup. J Urol 2000;163:442-445.

4. Herr HW. Partial nephrectomy for unilateral renal carcinoma and a normal contralateral kidney: 10-year follow-up. J Urol 1999;161:33-34.

5. Luciani RC, Greiner M, Clement JC, Houot A, Didierlaurent JF. Laparoscopic enucleation of a renal cell carcinoma. Surg Endosc 1994;8:1329-1331.
6. Wolf JS Jr, Seifman BD, Montie JE. Nephron-sparing surgery for suspected malignancy: Open surgery compared to laparoscopy with selective use of hand-assistance. J Urol 2000;163:1659-1664.

7. Guillonneau B, Bermudez H, Gholami S, et al. Laparoscopic partial nephrectomy for renal tumor: Single center experience comparing clamping and no clamping techniques of the renal vasculature. J Urol 2003;169:483-486.

8. Gill IS, Desai MM, Kaouk JH, et al. Laparoscopic partial nephrectomy for renal tumor: Duplicating open surgical techniques. J Urol 2002;167:469-477.

9. Yoshimura K, Okubo K, Ichiola K, Terada N, Matsuta Y, Arai Y: Laparoscopic partial nephrectomy with a microwave tissue coagulator for small renal tumor. J Urol 2001;165:1893-1896.

10. Gettman MT, Bishoff JT, Su LM, et al. Hemostatic laparoscopic partial nephrectomy: Initial experience with the radiofrequency coagulation-assisted technique. Urology 2001;58:8-11.

11. Jeschke K, Peschel R, Wakonig J, Schellander L, Bartsch G, Henning $\mathrm{K}$. Laparoscopic nephron-sparing surgery for renal tumors. Urology 2001;58:688-692.

12. Harmon WJ, Kavoussi LR, Bishoff JT. Laparoscopic nephron-sparing surgery for solid renal masses using the ultrasonic shears. Urology 2000;56:754-759.

13. Hoznek A, Salomon L, Antiphon P, et al. Partial nephrectomy with retroperitoneal laparoscopy. J Urol 1999;162:1922-1926.

14. Stifelman MD, Sosa RE, Nakada SY, Shichman SJ. Hand-assisted laparoscopic partial nephrectomy. J Endourol 2001;15:161-164.

15. Malloy TR, Schultz RE, Wein AJ, Carpiniello VL. Renal preservation utilizing neodymium:YAG laser. Urology 1986;27:99-103.

16. Rassweiler JJ, Abbou C, Janetschek G, Jeschke K. Laparoscopic partial nephrectomy: The European experience. Urol Clin North Am 2000;27:721-736.

Address reprint requests to: J. Stuart Wolf, Jr., M.D.

Dept. of Urology

University of Michigan

1500 E. Medical Center Dr.

Ann Arbor, MI 48109-0330

E-mail: wolfs@umich.edu 
This article has been cited by:

1. David Canes. 2008. Long-term oncological outcomes of laparoscopic partial nephrectomy. Current Opinion in Urology 18:2, 145-149. [CrossRef]

2. Clemens Baumann, Kerstin Westphalen, Heiko Fuchs, Helmut Oesterwitz, Johannes Hierholzer. 2007. Interventional Management of Renal Bleeding after Partial Nephrectomy. CardioVascular and Interventional Radiology 30:5, 828-832. [CrossRef]

3. Brian R. Lane, Andrew C. Novick. 2007. Nephron-sparing surgery. BJU International 99:5b, 1245-1250. [CrossRef]

4. Kyle J. Weld, Jaime Landman. 2006. Comparison of cryoablation, radiofrequency ablation and high-intensity focused ultrasound for treating small renal tumours. BJU International 96:9, 1224-1229. [CrossRef]

5. Nasser Albqami, G??nter Janetschek. 2005. Laparoscopic partial nephrectomy. Current Opinion in Urology 15:5, 306???311. [CrossRef] 